\title{
Leaf Rust and Stem Rust Resistance in Triticum dicoccoides Populations in Israel
}

\author{
Y. Anikster and J. Manisterski, Institute for Cereal Crops Improvement, Tel Aviv University, Ramat Aviv 69978, \\ Israel; D. L. Long, U.S. Department of Agriculture - Agricultural Research Service, Cereal Disease Laboratory, Uni- \\ versity of Minnesota, St. Paul 55108; and K. J. Leonard, Plant Pathology Department, University of Minnesota, St. \\ Paul 55108
}

\begin{abstract}
Anikster, Y., Manisterski, J., Long, D. L., and Leonard, K. J. 2005. Leaf rust and stem rust resistance in Triticum dicoccoides populations in Israel. Plant Dis. 89:55-62.

A total of 742 single plant accessions of Triticum dicoccoides were collected from 26 locations in Israel. All accessions were evaluated for leaf rust (Puccinia triticina) resistance in field plots at Tel Aviv, and subsets of 284 and 468 accessions were tested in the greenhouse in Tel Aviv and St. Paul, MN, respectively, for seedling resistance to leaf rust; 460 accessions were also tested for seedling resistance to stem rust (Puccinia graminis f. sp. tritici) in St. Paul. One accession was highly resistant to leaf rust in seedling tests in Tel Aviv, and 21 others had moderately susceptible to moderately resistant seedling resistance. Four accessions were highly resistant to leaf rust in seedling tests in St. Paul, and 11 were resistant to at least one stem rust race. Adult resistance to leaf rust was more common than seedling resistance among the accessions; 21 accessions had less than $25 \%$ leaf rust severity in field plots compared with 80 to $90 \%$ severity for highly susceptible accessions. Most of the accessions with effective adult plant resistance came from two nearby locations in Upper Galilee, a region where populations of $T$. dicoccoides are most extensive and genetically diverse. These accessions may provide valuable new partial resistance genes for durable protection against leaf rust in cultivated wheat.
\end{abstract}

Additional keywords: slow rusting resistance, wild emmer

Leaf rust, caused by Puccinia triticina, and stem rust, caused by $P$. graminis f. sp. tritici, are two of the most important diseases of wheat worldwide. Although stem rust has been largely controlled by resistance, it remains a potential threat, particularly in areas such as Australia, Argentina, and the Great Plains of the United States, where the climate is favorable for devastating epidemics. Leaf rust epidemics generally have been less destructive than the most severe stem rust epidemics, but leaf rust is a more widespread and persistent problem throughout the world. Much of the breeding effort against leaf rust in wheat has concentrated on genes for race-specific resistance. Race-specific resistance to leaf rust typically remains effective for only a few years, and recent studies suggest that the available resistance genes in hexaploid cultivated wheat, Triticum aestivum, have been nearly exhausted $(2,15)$.

With the diminishing success in finding new rust resistance genes in cultivars and

Corresponding author: K. J. Leonard

E-mail: kurtl@umn.edu

Accepted for publication 25 August 2004.

\section{DOI: 10.1094/PD-89-0055}

This article is in the public domain and not copyrightable. It may be freely reprinted with customary crediting of the source. The American Phytopathological Society, 2005. land races of $T$. aestivum, wheat breeders have turned their attention to wild relatives of wheat. Wild emmer, $T$. dicoccoides, is the closest wild relative to cultivated durum and bread wheat. Durum (AABB) and bread wheat (AABBDD) derived their A and $\mathrm{B}$ genomes from the tetraploid $T$. dicoccoides and are fully fertile in crosses with it. Thus, genes from $T$. dicoccoides can be transferred readily to cultivated wheats in crosses by recombination of homologous chromosomes $(4,18,24,25)$.

Native stands of $T$. dicoccoides can be found in small scattered populations across southern Turkey, northeastern Iraq, western Iran, and in the Caucasus, but the center of diversity for $T$. dicoccoides is in the region of northern Israel, northwestern Jordan, southwestern Syria, and eastern Lebanon $(6,19,25)$. Within Israel, the most extensive populations and the greatest genetic diversity of $T$. dicoccoides are in Jordan River watershed regions of eastern Galilee, eastern Samaria, and areas of the Golan Heights overlooking the Sea of Galilee $(20,25)$. In this area, uncultivated sites where grazing is controlled can support natural stands of $T$. dicoccoides as dense as cultivated wheat fields (6).

The objective of this study was to sample collections of $T$. dicoccoides from a diverse range of sites throughout northern Israel and to test the accessions for resistance to Israeli and North American isolates of $P$. triticina and $P$. graminis f. sp. tritici to identify useful sources of leaf rust and stem rust resistance for transfer to cultivated wheat. Tests for leaf rust resistance included exposure of the accessions to epidemics in inoculated field plots in Israel to screen for adult plant resistance as well as greenhouse tests for seedling resistance. Tests for stem rust resistance were done only with seedlings in the greenhouse.

\section{MATERIALS AND METHODS}

Seeds were collected from 742 single plants of $T$. dicoccoides from natural populations at 22 locations in nine regions of northern Israel and at three locations in Jerusalem in the Judean Mountains (Table 1, Fig. 1). Seed of single plant accessions were increased through two to five generations in screen houses and nurseries at Tel Aviv. All accessions are deposited in the Lieberman Germplasm Bank, Institute for Cereal Crops Improvement, Tel Aviv University. Accessions were grown in a field nursery at Tel Aviv, where they were inoculated with a bulk collection of $P$. triticina from both wild and cultivated wheats in Israel. Depending on seed availability, most of the accessions were also tested for seedling resistance in greenhouses at Tel Aviv and St. Paul, MN. At Tel Aviv, 284 accessions were tested as seedlings for resistance against a composite inoculum of $P$. triticina derived from aeciospores from Thalictrum speciosissimum, the alternate host for wheat leaf rust. These accessions came from locations in the following regions: Eastern Upper Galilee, the Hula Valley, Korazim, and Upper Galilee. At St. Paul, 468 accessions were tested as seedlings for resistance to a composite inoculum of $P$. triticina, and 460 were tested for resistance to a composite inoculum of $P$. graminis f. sp. tritici. Accessions tested in St. Paul came from the following regions: Eastern Upper Galilee, the Golan Heights, Mt. Hermon, the Hula Valley, the Judean Mountains, Lower Galilee, Korazim, Samaria, Upper Galilee, and the Valley of Esdraelon. Subsets of these accessions were also tested as seedlings against a single isolate of $P$. triticina from the United States (216 accessions) and against a single isolate of $P$. graminis f. sp. tritici (217 accessions).

Tel Aviv tests. Accessions of T. dicoccoides were planted in November in single $1-\mathrm{m}$ rows in a field nursery at Tel Aviv. 
Spreader rows of a leaf rust susceptible wheat cultivar were inoculated by spraying with a suspension of urediniospores of $P$. triticina in light mineral oil in February. Inoculum consisted of a bulk uredinial population of $P$. triticina derived from aeciospores from leaves of Thalictrum speciosissimum. The basidiospores that infected the T. speciosissimum plants were germinating teliospores from collections of telia obtained from cultivated wheat and wild emmer at multiple locations throughout Israel. The accessions of $T$. dicoccoides in the nursery were evaluated twice for leaf rust severity and reaction type in late April and early May.

Accessions tested for seedling resistance were grown in a 1:1 vermiculite:soil mixture in $10-\mathrm{cm}$-diameter pots. Four accessions were planted per pot with four seeds per accession and grown in a temperaturecontrolled greenhouse at $20 \pm 2^{\circ} \mathrm{C}$. At 7 to 10 days after planting, the seedlings were inoculated with urediniospores from the same bulk uredinial inoculum of $P$. triticina that was used in the field tests. Seedlings were sprayed with a suspension of urediniospores in light mineral oil, the oil was allowed to evaporate, and the inoculated plants were incubated overnight in a dew chamber before being returned to the greenhouse. At 12 to 14 days after inoculation, the plants were scored for infection type (IT) on a standard 0 to 4 scale (10). Infection types of 0 to 2 were produced by incubating the plants with to leaf rust in the greenhouse at Tel Aviv

considered resistant, ITs of 3 to 4 were considered susceptible, and ITs scored as 2,3 or 3,2 (i.e., with mixtures of IT2 and IT3 uredinia) were considered less than fully susceptible.

St. Paul tests. Accessions were tested for seedling resistance to leaf rust and stem rust in two tests each at St. Paul. In the first seedling test for leaf rust resistance, plants were inoculated with a single isolate of race TBBL of $P$. triticina, which was common in the United States. In the second leaf rust test, the seedlings were inoculated with a composite of 12 races: BBGL, CBGB, DBBG, KDBL, MFBL, MGBL, PBRG, PLMQ, PQRS, SBDJ, TBBL, and TLGG, all of which had been isolated from wheat fields in the United States. Virulence formulas for these races are derived as described in Long et al. (11). Together, this composite of races included virulence to Lr1, Lr2a, Lr2c, Lr3, Lr9, Lr16, Lr24, Lr26, Lr3ka, Lr11, Lr17, Lr30, LrB, Lr10, and $L r 14 a$, but not to $L r 18$. In the first seedling test for stem rust resistance, plants were inoculated with a single isolate of race TPMK of $P$. graminis $\mathrm{f}$. sp. tritici, which had been the most common wheat stem rust race in the United States for many years. In the second stem rust test, the seedlings were inoculated with a composite of four common races: QCCJ, QFCS, RCRS, and TPMK. This composite of stem rust races included virulence to Sr5, Sr21, Sr9e, Sr7b, Sr11, Sr8a, Sr9g, Sr36, Sr9b, Sr17, Sr9a, Sr9d, Sr10, and SrTmp, but not to $\operatorname{Sr} 6$ or $\operatorname{Sr} 30$.

Table 1. Locations where accessions of Triticum dicoccoides were collected in Israel

\begin{tabular}{lcccc}
\hline Location & Region $^{\mathbf{a}}$ & Altitude $(\mathbf{m})$ & Rainfall $(\mathbf{m m})$ & No. acc. \\
\hline Wered haGalil & EUG & 125 & 436 & 59 \\
Ammiad & EUG & 225 & 436 & 58 \\
Galabina & GOL & 125 & 420 & 10 \\
Katzarin & GOL & 325 & 420 & 1 \\
Nahal Devora & GOL & 425 & 420 & 12 \\
Nahal Orvim & GOL & 600 & 477 & 51 \\
Nahal Orvim Center & GOL & 450 & 477 & 7 \\
Yehudiyya Forest & GOL & -25 & 435 & 80 \\
Dov Mt. (Har Betarim) & HEM & 1,300 & 1,374 & 2 \\
Emek Maan & HEM & 1,375 & 1,374 & 3 \\
Mt. Hermon & HEM & 1,450 & 1,374 & 42 \\
Gonen & HVL & 200 & 551 & 56 \\
Jerusalem Univ. Givat Ram & JUM & 800 & 518 & 2 \\
Jerusalem, Shneler & JUM & 800 & 548 & 2 \\
Jerusalem Zoo & JUM & 800 & 548 & 4 \\
Almagor & KOR & 0 & 436 & 55 \\
Bet Qeshet & LGL & 200 & 544 & 52 \\
Gilboa Mt. Rd. & SAM & 350 & 370 & 4 \\
Dishon & UGL & 500 & 657 & 22 \\
Kefar Shammay-1 & UGL & 600 & 739 & 2 \\
Kefar Shammay-2 & UGL & 650 & 739 & 23 \\
Montfort & UGL & 300 & 786 & 3 \\
Nahal Dishon & UGL & 400 & 657 & 28 \\
Rosh Pinna-Zefat Rd. & UGL & 500 & 697 & 15 \\
Zefat & UGL & 500 & 697 & 64 \\
Givat haMore & VES & 350 & 454 & 94 \\
\hline
\end{tabular}

${ }^{\mathrm{a}}$ EUG $=$ Eastern Upper Galilee, GOL $=$ Golan Heights, HEM $=$ Mt. Hermon, HVL $=$ Hula Valley, $\mathrm{JUM}=$ Judean Mts., KOR $=$ Korazim, $\mathrm{LGL}=$ Lower Galilee, $\mathrm{SAM}=$ Samarian Mts., UGL $=$ Upper Galilee, VES = Valley of Esdraelon. Two populations (sites) of $T$. dicoccoides in close proximity at the Kefar Shammay location were sampled.

${ }^{b}$ Number of accessions per site.
In each test, seeds of the accessions to be inoculated were grown in vermiculite in 8 -cm-square plastic pots with three to five seeds each of four accessions planted in the corners of each pot. Glumes were removed from the seeds before planting. The pots were arranged in trays holding six pots each, and the plants were grown in a rust-free greenhouse for 7 days before inoculation. The seedlings were fertilized at 5 and 8 days after planting with a water soluble fertilizer (23-19-17, NPK) at $2.5 \mathrm{~g}$ per tray. On the seventh day after planting, the seedlings were inoculated by spraying them with a suspension of urediniospores in light mineral oil. The oil was allowed to evaporate for $30 \mathrm{~min}$, and the inoculated seedlings were placed in a dew chamber overnight at $18^{\circ} \mathrm{C}$. For stem rust, the dew chamber was programmed for fluorescent lights to turn on for 3 to $4 \mathrm{~h}$ before the dew chamber was opened to allow the seedlings to dry slowly for $2 \mathrm{~h}$ while the temperature rose gradually to $25^{\circ} \mathrm{C}$. When dry, the plants were returned to the greenhouse, where temperatures varied between 18 and $28^{\circ} \mathrm{C}$ daily. At 12 to 14 days after inoculation, the plants were scored for IT on a standard 0 to 4 scale $(10,22)$. Infection types of 0 to 2 were considered resistant, ITs of 3 to 4 were considered susceptible, and infection types scored as 2,3 or 3,2 (i.e., with mixtures of IT2 and 3 uredinia) were considered less than fully susceptible. In cases of mixed ITs, the more common IT was listed first.

Statistical tests. Correlation coefficients were calculated for early versus late leaf rust readings in field plot tests for accessions over all locations as well as for accessions within each of the eight regions from which more than 40 accessions were obtained.

\section{RESULTS}

Seedling resistance. Few of the accessions of T. dicoccoides tested in St. Paul showed a high level of seedling resistance to $P$. triticina. Only three of 468 accessions inoculated with the composite of races had predominantly low infection types (Table 2). Two of the three, accessions TD-93 and TD-97, developed some large susceptibletype uredinia in addition to flecks, indicating that these accessions may be susceptible to at least one race in the composite inoculum (note their susceptibility to race TBBL). Only accession TD-27 from Gonen was highly resistant to all components of the composite inoculum. Accession TD-27 was not tested with race TBBL, but the other two accessions resistant to most races in the composite were susceptible to race TBBL.

Eleven of the 460 accessions of $T$. dicoccoides tested in St. Paul showed some resistance to $P$. graminis $\mathrm{f}$. sp. tritici as seedlings (Table 2). Seven accessions had low or predominantly low infection types when inoculated with the composite of 
races of $P$. graminis $\mathrm{f}$. sp. tritici, but two of those accessions also developed some high infection types. Five accessions inoculated with race TPMK developed low infection types, although one had some high infection types as well. Only accession TD-73 from Zefat was highly resistant to both race TPMK and the composite inoculum of $P$. graminis f. $\mathrm{sp}$. tritici. One accession, TD-138 from Ammiad, which was resistant to race TPMK, was not tested with the composite inoculum.

All of the 284 accessions tested for resistance to the population of $P$. triticina in Tel Aviv developed seedling infection types of $2+$ or greater (Table 3 ). Twenty of the accessions had some combination of IT3 and IT2 uredinia, which could be interpreted as a moderately susceptible or moderately resistant reaction. Those 20 accessions were from Zefat, Ammiad, and Gonen. The two most resistant accessions, TD-277 (IT2+) and TD-259 (IT2-3-), were from Almagor.

Adult plant resistance. Distributions of leaf rust severity among accessions in field plots at Tel Aviv are shown in Figures 2 to 4. These accessions, which represent $95 \%$ of the total accessions tested, are from 12 populations of $T$. dicoccoides in eight regions of Israel. The most susceptible accessions were from Mt. Hermon, with nearly all of the accessions having 50 to $80 \%$ leaf rust severity in the early rust reading and 60 to $90 \%$ severity in the late rust reading (Fig. 2). Accessions from most other locations had mostly less than $50 \%$ leaf rust severity at the early rust reading. The exceptions were Nahal Orvim and Nahal Orvim Center in the Golan Heights (Fig. 2), Bet Qeshet in Lower Galilee (Fig. 3), Dishon and Nahal Dishon in Upper Galilee, and Kefar Shammay in Upper Galilee (Fig. 4), for which a considerable number of accessions had greater than 50\% leaf rust severity at the early rust reading.

The best adult plant resistance to leaf rust was in the populations of $T$. dicoccoides at Rosh Pinna-Zefat Road and Zefat in Upper Galilee, with the greatest proportion of accessions with low to moderate leaf rust severity at the late rust reading (Fig. 4). These populations also had the highest proportion of accessions with less than $20 \%$ leaf rust severity at the early rust reading. A small proportion of the populations at Yehudiyya Forest (Fig. 2) in the Golan Heights and at Bet Qeshet in Lower Galilee (Fig. 3) also had low leaf rust severity at the late leaf rust reading.

The 21 accessions of $T$. dicoccoides with less than $25 \%$ leaf rust severity at the late rust reading in plots at Tel Aviv are listed in Table 4. Thirteen of the most resistant accessions were from two populations in Upper Galilee, five were from the Golan Heights, two were from Lower Galilee, and one was from the Valley of Esdraelon. In addition to rust severity readings, each accession was rated for infection type in adult plants. All of the most resistant accessions received field infection type ratings with at least some combination of moderate resistance (MR) in the rating. Overall, most other accessions with greater leaf rust severity were rated as susceptible (S) or very susceptible (VS) in the field. The most resistant accessions ranged from boot stage of development (Feekes 10) to anthesis (Feekes 10.5) at the late rust reading.

Mean leaf rust severity readings for accessions from eight regions of Israel with more than 10 accessions each are shown in Table 5 for the early and late rust readings in field plots. Overall, accessions from Upper Galilee had the lowest mean leaf rust severity at the late reading, and accessions from Mt. Hermon had the greatest mean leaf rust severity. For Eastern Upper Galilee, Hula Valley, Korazim, and Lower Galilee, there was little correlation between the early and late rust readings in field plots at Tel Aviv. Over all 742 accessions tested, the correlation

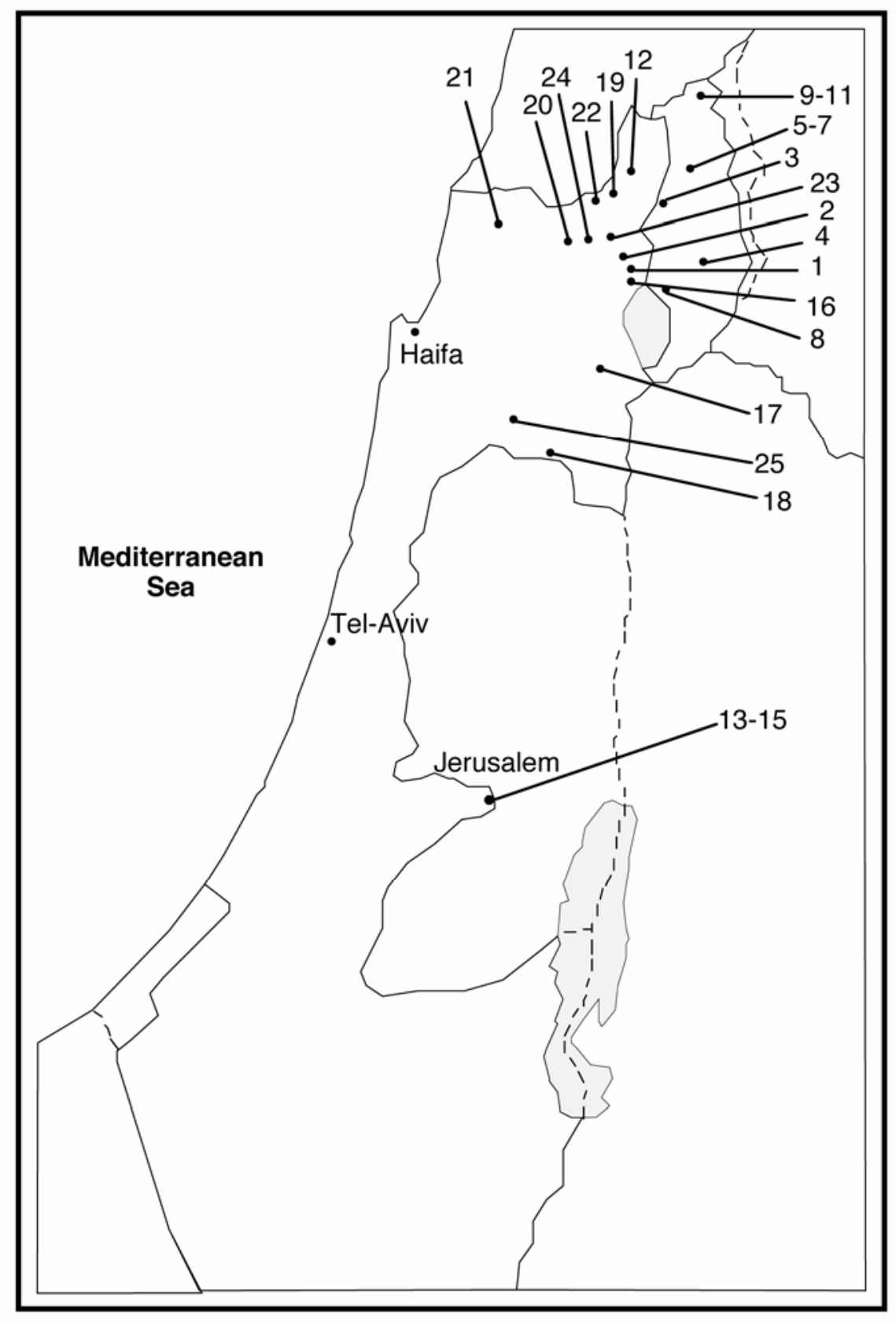

Fig. 1. Map of locations where accessions of Triticum dicoccoides were collected in Israel: 1, Wered haGalil; 2, Ammiad; 3, Galabina; 4, Katzarin; 5, Nahal Devora; 6, Nahal Orvim; 7, Nahal Orvim Center; 8, Yehudiyya Forest; 9, Dov Mt.; 10, Emek Maan; 11, Mt. Hermon; 12, Gonen; 13, Jerusalem Univ.; 14, Jerusalem, Shneler; 15, Jerusalem Zoo; 16, Almagor; 17, Bet Qeshet; 18, Gilboa Mt. Rd.; 19, Dishon; 20, Kefar Shammay; 21, Montfort; 22, Nahal Dishon; 23, Rosh Pinna-Zefat Rd.; 24, Zefat; 25, Givat haMore. Locations 1 and 2 are in Eastern Upper Galilee, 3 to 8 are in the Golan Heights, 9 to 11 are in the Mt. Hermon region, 12 is in the Hula Valley, 13 to 15 are in the Judean Mountains, 16 is in Korazim, 18 is in the Samarian Mountains, 17 and 19 to 24 are in Upper Galilee, and 25 is in the Valley of Esdraelon. 
between early and late rust severity readings was 0.560 , and on average leaf rust severity ratings were $33.1 \%$ higher in the late readings than in the early readings. Some accessions with effective adult plant resistance, such as TD-791, TD625, TD-385, TD-503, TD-785, and TD788, however, had late severity readings that were no higher than the early readings (Table 4).
For the sites from which seven or more accessions were collected, the average annual rainfall ranged from $420 \mathrm{~mm}$ at three locations in the Golan Heights to $1,374 \mathrm{~mm}$ at Mt. Hermon, and the average altitude ranged from $-25 \mathrm{~m}$ at Yehudiyya Forest to 1,450 m at Mt. Hermon (Table 1). In general, rainfall was positively correlated with altitude $(r=0.841)$. There was little correlation, however, between mean

Table 2. Accessions of Triticum dicoccoides from Israel with seedling resistance ${ }^{a}$ to Puccinia triticina or P. graminis in tests at St. Paul, MN

\begin{tabular}{|c|c|c|c|c|c|c|}
\hline \multirow[b]{2}{*}{ Accession } & \multirow[b]{2}{*}{ Location } & \multirow[b]{2}{*}{ Region } & \multicolumn{2}{|c|}{ P. triticina $^{\mathbf{b}}$} & \multicolumn{2}{|c|}{ P. graminis $^{\mathrm{c}}$} \\
\hline & & & Comp. & TBBL & Comp. & TPMK \\
\hline TD-126 & Ammiad & EUG & 3 & 3 & ;3 & 3 \\
\hline TD-132 & Ammiad & EUG & 3 & 3 & ; & $3 ;$ \\
\hline TD-138 & Ammiad & EUG & 3 & $\mathrm{nd}^{\mathrm{d}}$ & nd & ;3 \\
\hline TD-27 & Gonen & HVL & 0 ; & nd & 0 & 4 \\
\hline TD-33 & Gonen & HVL & 4 & 0 & 4 & 4 \\
\hline TD-51 & Gonen & HVL & 4 & 4 & $;-4$ & 4 \\
\hline TD-73 & Zefat & UGL & 4 & 4 & $1 \mathrm{c} 2$ & ; \\
\hline TD-84 & Zefat & UGL & 4 & 4 & 4 & ;/c \\
\hline TD-87 & Zefat & UGL & 4 & 4 & 4 & $; 2$ \\
\hline TD-93 & Zefat & UGL & ;3 & 4 & 4 & ;/c2 \\
\hline TD-97 & Zefat & UGL & $;-4$ & 4 & 4 & 4 \\
\hline TD-109 & Zefat & UGL & 3 & $3 ;$ & ; & $3 ;$ \\
\hline TD-111 & Zefat & UGL & 3 & 3 & ; & $3 ;$ \\
\hline
\end{tabular}

${ }^{a}$ Reaction types $;=$ fleck, $0=$ no visible reaction, $1=$ small uredinia with some necrosis or chlorosis, and $2=$ moderately small uredinia with chlorosis are classified as resistant. Greater than normal chlorosis is indicated by $\mathrm{c}$ in the reaction type. Reaction types $3=$ moderately large uredinia and $4=$ large uredinia are classified as susceptible. When reaction types were mixed, the predominant type is listed first.

${ }^{\mathrm{b}}$ Accessions were inoculated with a composite of races or with a single isolate of race TBBL of $P$. triticina.

c Accessions were inoculated with a composite of races or with a single isolate of race TPMK of $P$. graminis f. sp. tritici.

$\mathrm{d}$ nd $=$ not done.

Table 3. Accessions of Triticum dicoccoides from Israel with moderate resistance ${ }^{\mathrm{a}}$ as seedlings to Puccinia triticina in tests at Tel Aviv

\begin{tabular}{lccc}
\hline Accession & Location & Region & Comp. \\
\hline TD-147 & Ammiad & EUG & 3,2 \\
TD-156 & Ammiad & EUG & 3,2 \\
TD-174 & Ammiad & EUG & $3,(2)$ \\
TD-31 & Gonen & HVL & 3,2 \\
TD-35 & Gonen & HVL & 3 C,2+ \\
TD-37 & Gonen & HVL & $3,(2)$ \\
TD-57 & Gonen & HVL & 3,2 \\
TD-259 & Almagor & KOR & $2-3-$ \\
TD-277 & Almagor & KOR & $2+$ \\
TD-102 & Zefat & UGL & 3,2 \\
TD-105 & Zefat & UGL & 3,2 \\
TD-108 & Zefat & UGL & 3,2 \\
TD-110 & Zefat & UGL & 3,2 \\
TD-119 & Zefat & UGL & 3,2 \\
TD-67 & Zefat & UGL & 3,2 \\
TD-73 & Zefat & UGL & 3,2 \\
TD-77 & Zefat & UGL & 3,2 \\
TD-83 & Zefat & UGL & 3,2 \\
TD-89 & Zefat & UGL & 3,2 \\
TD-91 & Zefat & UGL & 3,2 \\
TD-92 & Zefat & UGL & 3,2 \\
TD-94 & Zefat & UGL & 3,2 \\
\hline
\end{tabular}

${ }^{\text {a }}$ Reaction type $2=$ moderately small uredinia with chlorosis are classified as resistant. Greater than normal chlorosis is indicated by $\mathrm{c}$ in the reaction type. Reaction types $3=$ moderately large uredinia and $4=$ large uredinia are classified as susceptible. When reaction types were mixed, the predominant type is listed first. Combinations of reaction types 3,2 or 2,3 are regarded as moderately susceptible or moderately resistant, respectively.

${ }^{\mathrm{b}}$ Seedlings were inoculated with a composite of races derived from aeciospores collected from the alternate host Thalictrum speciosissimum.

leaf rust severity of accessions in field plots at the late rust reading and either rainfall $(r=0.217)$ or altitude $(r=0.269)$ of the collection sites. Surprisingly, the most susceptible accessions on average were from Mt. Hermon, with the highest elevation and greatest average rainfall per year. At Zefat and the Rosh Pinna-Zefat Road, which had accessions with the most adult plant resistance to $P$. triticina, the annual rainfall was $697 \mathrm{~mm}$ and the elevation was $500 \mathrm{~m}$. Yehudiyya Forest, which had four of the 21 accessions with best adult plant resistance, is at an elevation of $-25 \mathrm{~m}$ and has an average rainfall of 435 $\mathrm{mm}$ per year. Although the Yehudiyya Forest is officially considered part of the Golan Heights region, it is located on the eastern shore of the Sea of Galilee, which is below sea level, rather than in the highlands above the Sea of Galilee, where several other collection sites in the Golan Heights are located.

\section{DISCUSSION}

Stem rust rarely occurs on $T$. dicoccoides in natural habitats in Israel, perhaps because the wheat cultivars grown in Israel all have effective resistance to $P$. graminis f. sp. tritici. Thus, cultivated wheat does not serve as a source of inoculum for stem rust infection of $T$. dicoccoides as it does for leaf rust infection. Leaf rust can be found late in the season every year in natural populations of $T$. dicoccoides in Israel (Y. Anikster, unpublished). Generally, the races of $P$. triticina identified from $T$. dicoccoides in Israel are the same as those found on cultivated wheat. Neither Berberis vulgaris, the alternate host for $P$. graminis, nor Thalictrum speciosissimum, the alternate host for $P$. triticina, occurs in Israel.

Eleven accessions of $T$. dicoccoides were resistant as seedlings to stem rust caused by $P$. graminis f. sp. tritici, but only accession TD-73 from Zefat was highly resistant to both race TPMK and the composite inoculum of $P$. graminis f. sp. tritici. This accession may possess valuable racespecific resistance to stem rust for introgression into cultivated wheats. Accession TD-27, which had seedling resistance to the leaf rust composite, also had seedling resistance to the stem rust composite and, therefore, is worthy of further study.

Nevo et al. (17) reported that a higher proportion, 22\%, of their accessions had seedling resistance to stem rust, but they used only a single isolate of $P$. graminis $\mathrm{f}$. sp. tritici to screen their accessions. The isolate used in their tests was obtained from Hordeum bulbosum in Israel and may have been less virulent to wheat than the isolates used in our study. On the other hand, McVey (14) found 14 unique genes for stem rust resistance among just 18 accessions of $T$. dicoccoides that he had selected from the U.S. Department of Agriculture, Small Grains Germplasm Collec- 

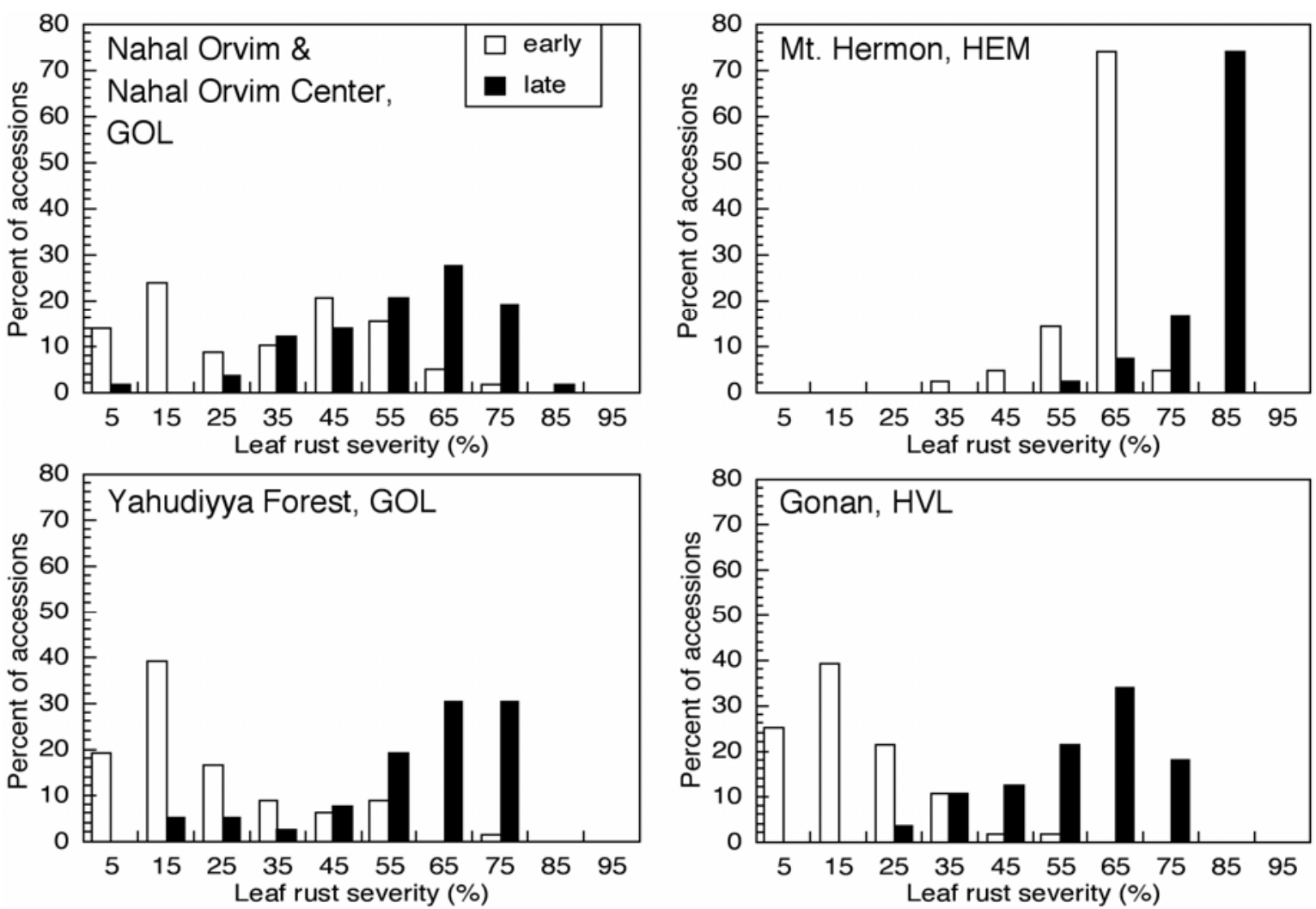

Fig. 2. Distribution of leaf rust severity among accessions of Triticum dicoccoides in a field nursery inoculated with Puccinia triticina near Tel Aviv. Accessions shown are from collections from four locations in Israel. GOL = Golan Heights, HEM = Mt. Hermon, and HLV = Hula Valley. Early severity readings were made when most accessions were in the flag leaf to boot stages of development (Feekes 9 to 10). Late severity readings were made when most accessions were in the heading to anthesis stages (Feekes 10.3 to 10.5).
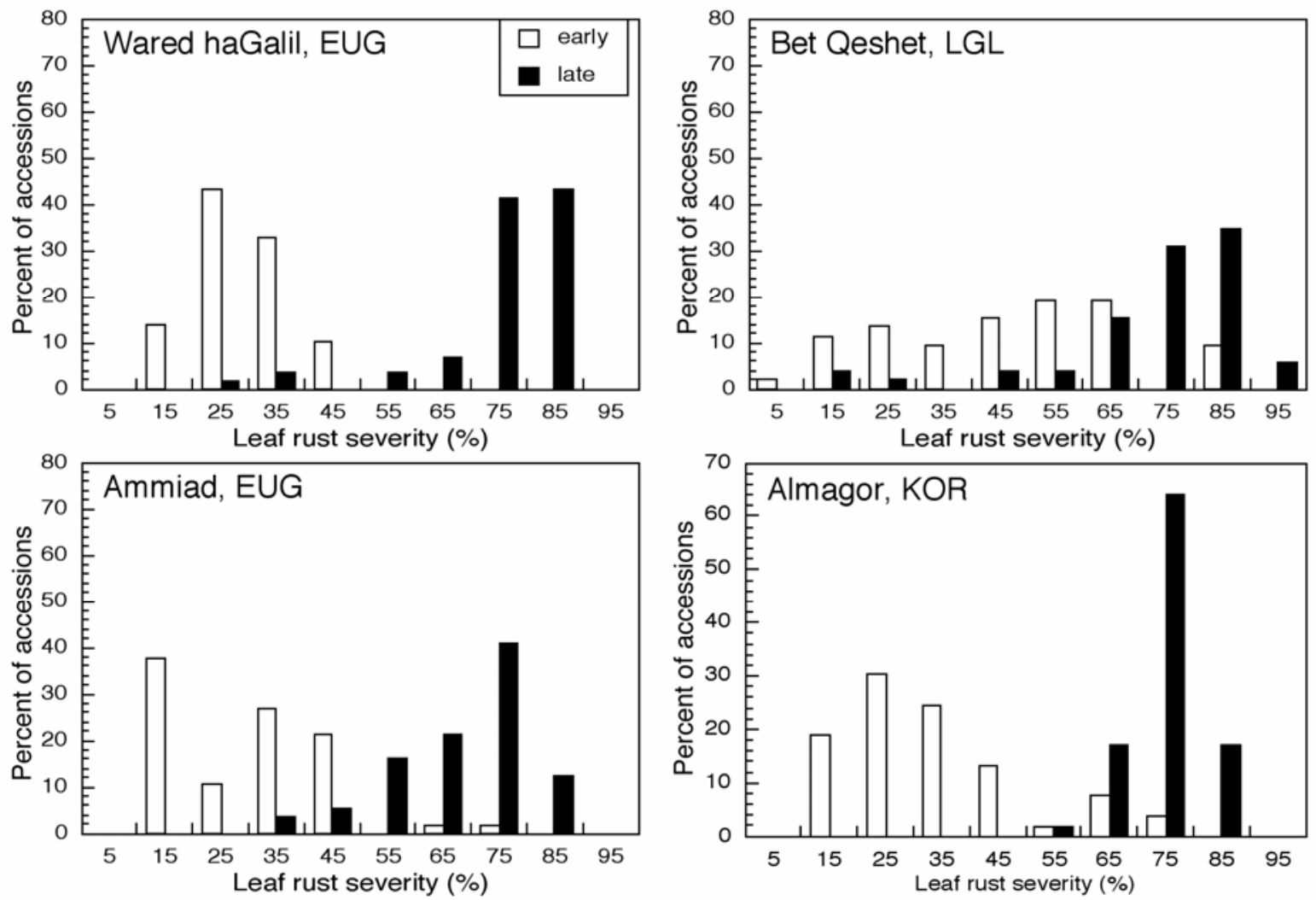

Fig. 3. Distribution of leaf rust severity among accessions of Triticum dicoccoides in a field nursery inoculated with Puccinia triticina near Tel Aviv. Accessions shown are from collections from four locations in Israel. EUG $=$ Eastern Upper Galilee, UGL $=$ Upper Galilee, and KOR $=$ Korazim. Early severity readings were made when most accessions were in the flag leaf to boot stages of development (Feekes 9 to 10). Late severity readings were made when most accessions were in the heading to anthesis stages (Feekes 10.3 to 10.5). 
tion, for testing with a series of 35 races of $P$. graminis f. sp. tritici. He considered three of the accessions to be potential sources of effective resistance to all of the common races of $P$. graminis $\mathrm{f}$. sp. tritici in the United States.

As reported in some previous studies with other collections of $T$. dicoccoides (15,23), seedling resistance to $P$. triticina was rare among the $T$. dicoccoides accessions in this study. The seedling resistance of three of the four accessions identified in the St. Paul tests may not be of immediate value for introgression into cultivated wheat germ plasm. These three accessions were resistant either to race TBBL or to the composite inoculum but not to both. Accession TD-27 was highly resistant to the composite inoculum but was not tested with race TBBL. This accession should be tested further.

Seedling resistance to $P$. triticina identified in greenhouse tests in Tel Aviv with one exception did not show low infection types typically seen with race-specific, hypersensitive resistance. The $2+$ infection type of accession TD-277 from Almagor is similar to that of some known $\mathrm{Lr}$ genes, but the other 21 accessions that were less than fully susceptible had combinations of infection types 3 and 2 that are not usually associated with hypersensitive resistance. Genes for adult plant resistance to leaf rust in wheat sometimes show 3,2 or 2,3 reactions as seedlings under some conditions, but many of the accessions with 3,2 seedling infection types in the greenhouse at Tel Aviv did not show adult plant resistance in field plots. Still, 13 of the accessions with 3,2 reactions in seedling tests at Tel Aviv came from Zefat, a site where several other accessions with good adult plant resistance were collected. These accessions with 3,2 or 2,3 reactions may be similar to the $14 \%$ of accessions of $T$. dicoccoides that Moseman et al. (15) recorded as moderately resistant, with seedling reactions of 4 to 6 on a 9-point scale. Moseman et al. (15) reported the greatest proportion of moderately resistant accessions from their collection at Yehudiyya.

In the long term, the most useful leaf rust resistance in the $T$. dicoccoides accessions is likely to be the adult plant resistance. Previous studies $(15,23)$ did not test accessions of $T$. dicoccoides at the adult stage. In our study, we found effective adult plant resistance to leaf rust in collections of $T$. dicoccoides from Rosh PinnaZefat Road, Zefat, Yehudiyya Forest, Bet
Qeshet, Givat haMore, and Nahal Orvim. The 21 most resistant accessions from these sites had less than $25 \%$ leaf rust severity at the time when most other accessions had 60 to $90 \%$. In contrast, no leaf rust resistance was found in the accessions from Mt. Hermon, which has the highest annual rainfall of any of the sites sampled in this study. Regions with higher rainfall might be expected to have greater leaf rust hazard and, therefore, to have evolved more resistance, but accessions from Mt. Hermon had the highest mean leaf rust severity of any collection in the field plot tests at Tel Aviv.

It is likely that the exposure of $T$. dicoccoides populations to leaf rust in Israel depends more on the density of the stands than on availability of moisture for infection. Sites that are too dry to support leaf rust infection may also be too dry to support extensive populations of $T$. dicoccoides. Anikster (1) and Dinoor et al. (3) have shown that the T. dicoccoides population at Ammiad is composed of a great majority of susceptible plants but is nearly free of disease. Leaf rust is common on cultivated wheat in Israel, but only a few $T$. dicoccoides plants in the Ammiad population were severely attacked in their natural
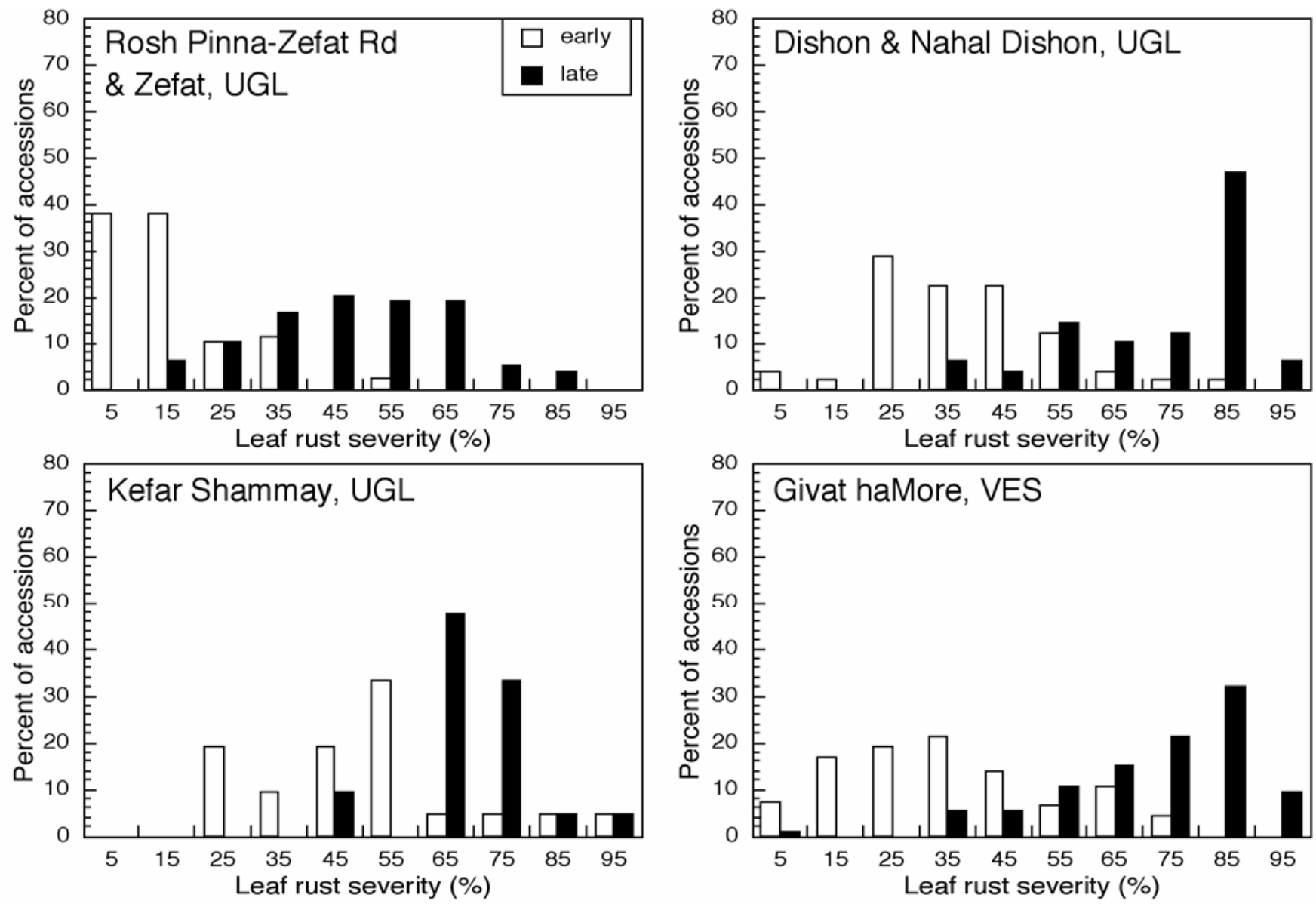

Fig. 4. Distribution of leaf rust severity among accessions of Triticum dicoccoides in a field nursery inoculated with Puccinia triticina near Tel Aviv. Accessions shown are from collections from four locations in Israel. UGL = Upper Galilee and VES = Valley of Esdraelon. Early severity readings were made when most accessions were in the flag leaf to boot stages of development (Feekes 9 to 10). Late severity readings were made when most accessions were in the heading to anthesis stages (Feekes 10.3 to 10.5 ). 
site. When seeds from $T$. dicoccoides plants at Ammiad were sown in nurseries, however, the resulting plants developed up to $90 \%$ leaf rust severity. In our study, the sites with the greatest numbers of accessions with adult plant resistance to leaf rust were in Galilee or adjacent areas where natural populations of $T$. dicoccoides are most dense and genetically diverse in Israel. According to Noy-Meir (20), annual rainfall of 400 to $500 \mathrm{~mm}$ may be optimal for natural populations of $T$. dicoccoides. In our study, the accessions from Rosh Pinna, Zefat, and Nahal Orvim Center, with average annual rainfall of 697, 697, and $477 \mathrm{~mm}$, respectively, had the lowest mean leaf rust severity in field plot tests. The sites at Rosh Pinna, Zefat, and Yehudiyya Forest (435 mm annual rainfall) had the greatest numbers of accessions with less than $25 \%$ leaf rust severity in the field tests. Mamluk and Van Slageren (13) studied the leaf rust resistance of accessions of $T$. dicoccoides from southern Turkey, southern Syria, and northwestern Jordan. They found that only the accessions from northwest Jordan showed a relatively high proportion of accessions with field resistance to leaf rust.

In surveys at Ammiad, leaf rust was evident only toward the end of the growing season $(1,3)$. This is consistent with reports of Mamluk et al. (12) for leaf rust in cultivated wheat in southern Syria. Dinoor et al. (3) suggested that the late appearance of disease may limit selection pressure for seedling resistance and favor adult plant resistance in $T$. dicoccoides. This could account for the greater frequency of adult plant resistance than seedling resistance in the accessions from sites where populations of $T$. dicoccoides are most profuse and the general lack of resistance in accessions from peripheral sites with limited populations.

Individual genes for adult plant resistance to leaf rust can show enhanced effectiveness when combined in wheat cultivars (5). Minor genes for partial resistance to leaf rust in wheat have been shown to have additive effects $(7,9)$. Combinations of genes for partial resistance from different gene pools might lead to very high levels of resistance to leaf rust (7). At least one gene for adult plant resistance, Lr34, has proven to be highly durable in widespread use and, therefore, appears to be race-nonspecific (8). The resistant accessions of $T$. dicoccoides identified in the field plots at Tel Aviv are a potential source of new genes for durable resistance to $P$. triticina that could be introgressed relatively easily into cultivated wheat. Reinhold et al. (21) were able to incorporate genes for additive "minor effects" for stripe rust resistance into cultivated wheat from $T$. dicoccoides accessions from Turkey. From our studies, Upper Galilee appears to be the most promising region in Israel to search for more populations of $T$. dicoccoides with genes for adult plant resistance to leaf rust. We agree with Nevo (16) that T. dicoccoides is "a very rich, but as yet largely untapped, genetic resource for wheat improvement."

\section{LITERATURE CITED}

1. Anikster, Y. 2001. Host-parasite relations in a population of wild emmer in eastern Galilee. Isr. J. Plant Sci. 49:S37-S41.

2. Bai, D., and Knott, D. R. 1994. Genetic studies of leaf and stem rust resistance in six acces-

Table 5. Correlation of early and late field readings for severity of leaf rust in accessions of Triticum dicoccoides from eight regions ${ }^{\mathrm{a}}$ of Israel

\begin{tabular}{lcccc}
\hline & & \multicolumn{2}{c}{ Mean severity (\%) } & \\
\cline { 3 - 4 } Region & No. accessions ${ }^{\mathbf{b}}$ & Early & Late & Corr. \\
\hline Eastern Upper Galilee & 114 & 25.7 & 67.1 & 0.186 \\
Golan Heights & 160 & 32.8 & 63.8 & 0.485 \\
Mt. Hermon & 47 & 65.5 & 83.5 & 0.790 \\
Hula Valley & 56 & 21.4 & 61.3 & 0.262 \\
Korazim & 53 & 30.4 & 69.7 & 0.051 \\
Lower Galilee & 52 & 42.6 & 68.0 & 0.287 \\
Upper Galilee & 154 & 24.6 & 55.5 & 0.647 \\
Valley of Esdraelon & 94 & 30.3 & 67.2 & 0.705 \\
All locations & 742 & 31.9 & 65.0 & 0.560 \\
\hline
\end{tabular}

a The Judean Mountains (eight accessions) and the Samarian Mountains (four accessions) are excluded.

b Total number of accessions tested in field plots at Tel Aviv.

Table 4. Accessions of Triticum dicoccoides from Israel with effective adult plant resistance in field tests ${ }^{\mathrm{a}}$ at Tel Aviv

\begin{tabular}{|c|c|c|c|c|c|c|c|c|}
\hline \multirow[b]{2}{*}{ Accession } & \multirow[b]{2}{*}{ Location } & \multirow[b]{2}{*}{ Regions $^{\mathbf{b}}$} & \multicolumn{3}{|c|}{ Early rust severity reading } & \multicolumn{3}{|c|}{ Late rust severity reading } \\
\hline & & & $\%$ & Reaction $^{c}$ & $\mathbf{G S}^{\mathbf{d}}$ & $\%$ & Reaction & GS \\
\hline TD-503 & Nahal Orvim & GOL & 10 & MR MS & 9 & 10 & MR MS & 10 \\
\hline TD-358 & Yehudiyya Forest & GOL & 2 & R MR & 10 & 20 & MR & 10.5 \\
\hline TD-359 & Yehudiyya Forest & GOL & $5-10$ & R MR MS & 10 & 20 & MR & 10.5 \\
\hline TD-360 & Yehudiyya Forest & GOL & 5 & R MR MS & $9-10$ & 20 & MR & 10.5 \\
\hline TD-380 & Yehudiyya Forest & GOL & $5-10$ & R MR MS & 10 & 20 & MR MS & 10.5 \\
\hline TD-719 & Bet Qeshet & LGL & 5 & R MR & 9 & 15 & MR MS & 10.3 \\
\hline TD-385 & Bet Qeshet & LGL & 10 & MR MS S & 9 & 10 & R MR & 10.3 \\
\hline TD-777 & Rosh Pinna-Zefat Rd. & UGL & 2 & R MR & $7-8$ & 15 & R MR & 10.3 \\
\hline TD-778 & Rosh Pinna-Zefat Rd. & UGL & 5 & R MR & 9 & $5-10$ & R MR & 10 \\
\hline TD-779 & Rosh Pinna-Zefat Rd. & UGL & 10 & R MR & 9 & 20 & R MR & 10.3 \\
\hline TD-780 & Rosh Pinna-Zefat Rd. & UGL & 10 & $\mathrm{R}$ & 9 & 20 & MR & 10.3 \\
\hline TD-783 & Rosh Pinna-Zefat Rd. & UGL & 10 & R MR & 10 & 20 & MR & 10.3 \\
\hline TD-785 & Rosh Pinna-Zefat Rd. & UGL & 20 & R MR & 9 & 20 & R MR & 10.3 \\
\hline TD-788 & Rosh Pinna-Zefat Rd. & UGL & 20 & R MR & 9 & 20 & R MR & 10.3 \\
\hline TD-791 & Rosh Pinna-Zefat Rd. & UGL & 20 & R MR & 10 & 10 & R MR & 10.3 \\
\hline TD-110 & Zefat & UGL & 2 & R MR & 10.3 & 20 & MR & 10.5 \\
\hline TD-114 & Zefat & UGL & 5 & MR MS & 9 & 20 & MR MS & 10.3 \\
\hline TD-75 & Zefat & UGL & $5-10$ & MR & 10 & 15 & R MR MS & 10.3 \\
\hline TD-94 & Zefat & UGL & 2 & R MR (MS) & 10.3 & 20 & MR MS & 10.5 \\
\hline TD-99 & Zefat & UGL & 2 & R MR & 9 & $10-15$ & R MR & 10.5 \\
\hline TD-625 & Givat haMore & VES & 5 & MR & 9 & 5 & MR & 10.3 \\
\hline
\end{tabular}


sions of Triticum turgidum var. dicoccoides. Genome 37:405-409.

3. Dinoor, A., Eshed, N., Ecker, R., GerechterAmitai, Z., Solel, Z., Manisterski, J., and Anikster, Y. 1991. Fungal diseases of wild tetraploid wheat in a natural stand in northern Israel. Isr. J. Bot. 40:481-500.

4. Dyck, P. L. 1994. The transfer of leaf rust resistance from Triticum turgidum ssp. dicoccoides to hexaploid wheat. Can. J. Plant Sci. 74:671-673.

5. German, S. E., and Kolmer, J. A. 1992. Effect of gene Lr34 in the enhancement of resistance to leaf rust of wheat. Theor. Appl. Genet. 84:97-105.

6. Harlan, J. R., and Zohary, D. 1966. Distribution of wild wheats and barley. Science 153:1074-1080.

7. Jacobs, T., and Broers, L. H. M. 1989. The inheritance of host plant effect on latency period of wheat leaf rust in spring wheat. II. Estimation of gene action and number of effective factors in $F_{1}, F_{2}$, and backcross generations. Euphytica 44:197-206.

8. Kolmer, J. A. 1996. Genetics of resistance to wheat leaf rust. Annu. Rev. Phytopathol. 34:435-455.

9. Lee, T. S., and Shaner, G. 1985. Transgressive segregation of length of latent period in crosses between slow leaf-rusting wheat cultivars. Phytopathology 75:643-647.

10. Long, D. L., and Kolmer, J. A. 1989. A North
American system of nomenclature for Puccinia recondita $\mathrm{f}$. $\mathrm{sp}$. tritici. Phytopathology 79:525-529.

11. Long, D. L., Kolmer, J. A., Leonard, K. J., and Hughes, M. E. 2002. Physiologic specialization of Puccinia triticina on wheat in the United States in 2000. Plant Dis. 86:981-986.

12. Mamluk, O. F., Al-Ahmed, M., and Makki, M. A. 1990. Current status of wheat diseases in Syria. Phytopathol. Mediterr. 29:143-150.

13. Mamluk, O. F., and Van Slageren, M. W. 1993. Resistance to common bunt, yellow rust, leaf rust and Septoria tritici blotch in wild einkorn and wild emmer wheat. Phytopathol. Mediterr. 32:14-19.

14. McVey, D. V. 1991. Reaction of a group of related wheat species (AABB gemome and an AABBDD) to stem rust. Crop Sci. 31:11451149 .

15. Moseman, J. G., Nevo, E., Gerechter-Amitai, Z. K., El-Morshidy, M. A., and Zohary, D. 1985. Resistance of Triticum dicoccoides collected in Israel to infection with Puccinia recondita tritici. Crop Sci. 25:262-265.

16. Nevo, E. 2001. Genetic resources of wild emmer, Triticum dicoccoides, for wheat improvement in the third millennium. Isr. J. Plant Sci. 49:S77-S91.

17. Nevo, E., Gerechter-Amitai, Z., and Beiles, A. 1991. Resistance of wild emmer wheat to stem rust: Ecological, pathological and allozyme associations. Euphytica 53:121-130.
18. Nevo, E., Golenberg, E., Beiles, A., Brown, A H. D., and Zohary, D. 1982. Genetic diversity and environmental associations of wild wheat, Triticum dicoccoides, in Israel. Theor. Appl. Genet. 62:241-254

19. Nevo, E., Moseman, J. G., Beiles, A., and Zohary, D. 1985. Patterns of resistance of Israeli wild emmer wheat to pathogens I. Predictive method by ecology and allozyme genotypes for powdery mildew and leaf rust. Genetica 67:209-222

20. Noy-Meir, I. 2001. Ecology of wild emmer in Mediterranean grasslands in Galilee. Isr. J. Plant Sci. 49:S43-S52.

21. Reinhold, M., Sharp, E. L., and GerechterAmitai, Z. 1983. Transfer of additive "minor effect" genes for resistance to Puccinia striiformis from Triticum dicoccoides into Triticum durum and Triticum aestivum. Can. J. Bot. 61:2702-2708.

22. Roelfs, A. P., and Martens, J. W. 1988. An international system of nomenclature for Puccinia graminis f. sp. tritici. Phytopathology 78:526-533.

23. The, T. T., Nevo, E., and McIntosh, R. A. 1993. Responses of Israeli wild emmers to selected Australian pathotypes of Puccinia species. Euphytica 71:75-81.

24. Valkoun, J. J. 2001. Wheat pre-breeding using wild progenitors. Euphytica 119:17-23.

25. Zohary, D. 1983. Wild genetic resources of crops in Israel. Isr. J. Bot. 32:97-129. 